\title{
Physiological and radiological characterisation of patients diagnosed with chronic obstructive pulmonary disease in primary care
}

\author{
C O'Brien, P J Guest, S L Hill, R A Stockley
}

\begin{abstract}
Background-Chronic obstructive pulmonary disease (COPD) is common although often poorly characterised, particularly in primary care. However, application of guidelines to the management of such patients needs a clear understanding of the phenotype. In particular, the British guidelines for the management of COPD recommend that the diagnosis is based on appropriate symptoms and evidence of airflow obstruction as determined by a forced expiratory volume in one second $\left(F E V_{1}\right)$ of $<80 \%$ of the predicted value and an $F E V_{1} / V C$ ratio of $<70 \%$.
\end{abstract}

Methods-A study was undertaken of 110 patients aged 40-80 years who had presented to their general practitioner with an acute exacerbation of COPD. The episode was treated at home and, when patients had recovered to the stable state (two months later), they were characterised by full lung function tests and a high resolution computed tomographic (HRCT) scan of the chest.

Results-There was a wide range of impairment of $\mathrm{FEV}_{1}$ which was in the normal range $(\geqslant 80 \%)$ in $30 \%$, mildly impaired $(60-79 \%)$ in $18 \%$, moderately impaired (40-59\%) in $33 \%$, and severely impaired $(<40 \%)$ in $19 \%$ of patients. A reduced $\mathrm{FEV}_{1} / \mathrm{VC}$ ratio was present in all patients with an $\mathrm{FEV}_{1}$ of $<80 \%$ predicted but also in $41 \%$ of those with an $\mathrm{FEV}_{1}$ of $\geqslant 80 \%$ predicted. Only $5 \%$ of patients had a substantial bronchodilator response suggesting a diagnosis of asthma. Emphysema was present in $51 \%$ of patients and confined to the upper lobes in most $(73 \%$ of these patients). HRCT evidence of bronchiectasis was noted in $29 \%$ of patients and was predominantly tubular; most (81\%) were current or ex-smokers. A solitary pulmonary nodule was seen on $9 \%$ of scans and unsuspected lung malignancy was diagnosed in two patients.

Conclusions-This study confirms that COPD in primary care is a heterogeneous condition. Some patients do not fulfil the proposed diagnostic criteria with $\mathrm{FEV}_{1}$ of $\geqslant 80 \%$ predicted but they may nevertheless have airflow obstruction. Bronchiectasis is common in this group of patients, as is unsuspected malignancy. These findings should be considered when developing recommendations for the investigation and management of COPD in the community.

(Thorax 2000;55:635-642)

Keywords: chronic obstructive pulmonary disease; bronchiectasis; lung function tests; radiology

By the year 2020 chronic obstructive pulmonary disease (COPD) is predicted to become the fifth leading cause of morbidity and mortality. ${ }^{1}$ Already in primary care it accounts for 2665 consultations per 10000 person years at risk $^{2}$ which is comparable to that for angina pectoris. Despite being a major health care burden, clinical management has mainly been empirical until publication of the British Thoracic Society guidelines for the management of $\mathrm{COPD}^{3}$ intended for both primary and secondary care physicians.

It is well recognised that the generic term COPD includes patients with a variety of conditions including emphysema, chronic bronchitis, and chronic asthma which may occur alone or in combination..$^{4-6}$ The common feature of these disorders is longstanding airflow obstruction which does not change markedly over a period of months, ${ }^{37}$ although it is accepted that there may be some reversibility of the airflow obstruction in response to bronchodilators. ${ }^{357}$ The British Thoracic Society (BTS) recommends the use of spirometric tests to detect airflow obstruction and confirm the diagnosis of COPD by impairment in forced expiratory volume in one second $\left(\mathrm{FEV}_{1}\right)$ with little response to inhaled bronchodilators. However, spirometric testing is not widely available in primary care and thus the diagnosis of COPD is often based on clinical symptoms and signs, even though these correlate poorly with lung function. ${ }^{8-10}$

Patients in primary care with a diagnosis of COPD may therefore be more heterogeneous with respect to their underlying disorder and degree of lung function impairment than those diagnosed in secondary care. The situation is further compounded by difficulty in differentiating COPD from asthma in primary care; this 
will be critical for the provision of health services and future research in COPD, which will focus increasingly on primary care. For instance, many phase IV clinical trials are carried out in primary care and the results are used to determine clinical practice, often across all health care sectors.

It is therefore important to document the nature of COPD diagnosed in primary care in order to determine the relevance of national guidelines to the management of these patients and interpretation of clinical trials performed in the community.

We have studied 110 patients with a primary care diagnosis of COPD who presented to their general practitioner with an acute exacerbation of their disease. All patients underwent full lung function testing and CT scanning with a high resolution algorithm when they had recovered to their stable state to determine their physiological and radiological characteristics.

\section{Methods}

From September 1996 until August 1998 we studied patients aged $40-80$ years managed in the community whose general practitioner had diagnosed an acute exacerbation of COPD associated with sputum production. Forty four general practitioners in 29 surgeries participated. Six surgeries referred more than 10 patients each, a further six practices each referred 5-10 patients, and the remaining surgeries entered 1-4 patients. All general practitioners used the same criteria to define an exacerbation, including one or more of increased breathlessness, sputum volume and purulence, with or without worsening of any other symptoms (cough, increased sputum viscosity, wheeze, chest pain, malaise, fever, chills) that prompted the patient to seek advice and treatment from their general practitioner. Patients who were thought to require treatment with oral corticosteroids or hospital admission were excluded from the study. Treatment for the exacerbation was given according to the study protocol: patients with (muco)purulent sputum received an antibiotic and patients with mucoid sputum an inhaled steroid or placebo. Patients were reviewed two months later when they had recovered to their stable clinical state, defined as complete resolution of the acute symptoms without a change in medication or symptoms in the previous four weeks. Full lung function tests and a high resolution CT scan of the chest were carried out on the same day. A total of 182 patients were referred for entry and 131 were recruited into the study. Among the 51 patients who did not enter the study, 18 declined to participate, 11 had been unstable in the four weeks before the current exacerbation, 11 did not have an exacerbation, six were unable to provide a sputum sample, four needed hospitalisation or treatment with prednisolone, and one patient was blind. Twenty one patients participated in the study but were not characterised with lung function tests and a CT scan (16 patients declined, three were found to have a fresh exacerbation on the day of the assessment, one patient was lost to follow up, and one died of overwhelming pneumonia).

Where possible, a spontaneously expectorated sputum sample was collected on the morning of the assessment day. Its macroscopic appearance was assessed by experienced laboratory staff and allocated a number depending on the degree of purulence by reference to a standard colour chart (Bronkotest, Heredilab, Utah, USA). This chart was based on the principle that increasing colouration of sputum from mucoid (0-2) to mucopurulent (3-5) and purulent (6-8) occurs as the concentration of myeloperoxidase rises, reflecting increasing numbers of neutrophils in the airway secretions. ${ }^{11}$

Full lung function tests were performed according to national guidelines. ${ }^{12}$ Dynamic lung volumes $\left(\mathrm{FEV}_{1}\right.$, forced vital capacity (FVC), and relaxed vital capacity (VC)) were measured on a wedge bellows spirometer (Vitalograph, Buckinghamshire, UK). Static lung volumes were measured by helium dilution and gas transfer by the single breath carbon monoxide method using the Benchmark system from Morgan Medical (Kent, UK).

Reversibility of airflow obstruction was assessed by spirometric tests 20 minutes after administration of inhaled salbutamol $(400 \mu \mathrm{g})$. To determine any additional effect inhaled ipratropium bromide $(60 \mu \mathrm{g})$ was then administered and spirometric testing was repeated after a further 45 minutes. Both drugs were given via a large volume spacer device under the supervision of trained staff and all measurements were corrected to body temperature and pressure saturated with water vapour (BTPS). Reference equations for the calculation of predicted values were those produced by the European Community for Steel and Coal. ${ }^{12}$

After lung function tests had been completed a high resolution CT scan of the chest was performed. One millimetre slices were obtained at $10 \mathrm{~mm}$ intervals in inspiration with an acquisition time of one second for each slice. Window width was set at 2000 Hounsfield units (HU) and window level at $-700 \mathrm{HU}$. Scans were initially reported by a specialist respiratory radiologist and then reviewed again, without knowledge of the first report, six months later together with a chest physician for the presence of bronchiectasis. The presence and type of bronchiectasis were determined by consensus. Criteria for the diagnosis of bronchiectasis were lack of tapering, visibility of bronchi within $1 \mathrm{~cm}$ of the pleura and bronchial dilatation (bronchial diameter larger than that of the accompanying pulmonary artery; avoiding slices close to bronchial bifurcation). ${ }^{13}$ Bronchiectasis was described as cystic, varicose, or tubular (cylindrical) according to the criteria first described by Naidich et $a l^{14}$ and recently reviewed by Hansell. ${ }^{13}$

Emphysema was identified as areas of well demarcated low density without a perceptible wall associated with attenuation and distortion of the lung vasculature. Changes ranged from small focal areas of destruction with normal 
Table 1 Demographic information for all patients and for those with full lung function tests stratified by degree of impairment of FEV

\begin{tabular}{|c|c|c|c|c|c|}
\hline & \multirow[b]{2}{*}{$\begin{array}{l}\text { All } \\
(n=110)\end{array}$} & \multicolumn{4}{|c|}{ Impairment of $F E V_{1}(n=108)$} \\
\hline & & $\begin{array}{l}\text { None } \\
(n=32)\end{array}$ & $\begin{array}{l}\text { Mild } \\
(n=19)\end{array}$ & $\begin{array}{l}\text { Moderate } \\
(n=36)\end{array}$ & $\begin{array}{l}\text { Severe } \\
(n=21)\end{array}$ \\
\hline $\mathrm{Age}^{\mathrm{a}}$ & $66.5(60-72)$ & $63(58-69)$ & $64(57-69)$ & $68(62-74)$ & $69(63.5-75.5)$ \\
\hline Male:female & $64: 46$ & $15: 17$ & $10: 9$ & $20: 16$ & $18: 3^{\star \star}$ \\
\hline \multicolumn{6}{|l|}{ Smoking status } \\
\hline Current & 50 & $13(41 \%)$ & $10(52.5 \%)$ & $21(58 \%)$ & $5(24 \%)$ \\
\hline $\mathrm{Ex}$ & 54 & $17(53 \%)$ & $7(37 \%)$ & $14(39 \%)$ & $15(71 \%)^{\star}$ \\
\hline Never & 6 & $2(6 \%)$ & $2(10.5 \%)$ & $1(3 \%)$ & $1(5 \%)$ \\
\hline Pack years $^{a}$ & $45(23-70)$ & $37(16-60)$ & $48(22.5-104)$ & $57(32-81)$ & $34(20-75)$ \\
\hline Treatment with inhaled steroids & 53 & $11(34 \%)$ & $6(32 \%)$ & $17(47 \%)$ & $17(81 \%)^{\star \star \star}$ \\
\hline Co-morbidity ${ }^{\mathrm{b}}$ & 44 & 10 & 10 & 13 & 11 \\
\hline
\end{tabular}

${ }^{a}$ Data are median with interquartile range in parentheses. ${ }^{b}$ The total number of patients with co-morbidity is shown (see text for details).

${ }^{\star} \mathrm{p}=0.02,{ }^{\star \star} \mathrm{p}=0.0035,{ }^{\star \star \star} \mathrm{p}<0.0005$ compared with other groups.

surrounding lung (centrilobular emphysema) to frank confluent destruction (panacinar or advanced centrilobular emphysema). ${ }^{15}$ Emphysema was characterised as limited when confined only to the upper lobes and extensive when it also involved the lower and/or middle lobes.

Data with a normal distribution are presented as the mean (SD) and were compared statistically using the Student's $t$ test for unpaired data. Multiple means were compared with the one way ANOVA using Tukey's test for post-hoc comparison only when the results of the ANOVA were significant at a level of $\mathrm{p}<0.05$. Data was logarithmically transformed where necessary to fulfil the requirement for equal variances. Any data with a skewed distribution were summarised as medians with quartiles and compared using non-parametric tests. Proportions were compared using the $\chi^{2}$ test (Fisher's exact test where appropriate). Two sided tests were used. Statistical analysis was carried out using SPSS version 8.0.

The study was approved by the University of Birmingham NHS Trust Research Ethics Committee.

\section{Results}

A total of 110 patients underwent HRCT scanning of the chest and 108 completed lung function tests technically valid for analysis (although a further two did not complete bronchodilator reversibility testing and one patient declined to have static lung volumes measured).

Table 2 Pre-bronchodilator spirometric data for 108 patients separated by degree of impairment of $F E V_{1}$

\begin{tabular}{|c|c|c|c|c|}
\hline & \multicolumn{4}{|c|}{ Impairment of FEV $V_{1}$} \\
\hline & None $(n=32)$ & Mild $(n=19)$ & Moderate $(n=36)$ & Severe $(n=21)$ \\
\hline $\mathrm{FEV}_{1}(\mathrm{l})$ & $2.31(0.61)$ & $1.77(0.44)^{\star \star}$ & $1.27(0.32)^{\star \star \star}$ & $0.74(0.19)^{\star \star \star}$ \\
\hline $\mathrm{FEV}_{1}(\%$ predicted $)$ & $94.7 \quad(11.0)$ & $69.6(6.2)$ & $51.4(5.6)$ & $29.3(7.0)$ \\
\hline FVC (1) & $3.3(0.8)$ & $2.9(0.6)$ & $2.8 \quad(0.9)$ & 2.25 (0.8) t+十 \\
\hline FVC (\% predicted) & $108.5 \quad(12.7)$ & $93.1(15.1)^{\star \star}$ & $87.4 \quad(15.9)$ & $67.0(17.2)^{\star \star \star}$ \\
\hline VC (1) & $3.38(0.88)$ & $2.99(0.61)$ & $2.97(0.9)$ & $2.47(0.75) \dagger \dagger$ \\
\hline VC ( $\%$ predicted $)$ & 110.9 (13.3) & $96.0(15.2)^{\star \star}$ & $93.8 \quad(16.9)$ & $73.6(15.8)^{\star \star \star}$ \\
\hline $\mathrm{FEV}_{1} / \mathrm{FVC}(\%)$ & $70.6(9.2)$ & $61.1(10.4)$ & $47.2(9.6)^{\star \star}$ & $34.0(7.3)^{\star}$ \\
\hline $\mathrm{FEV}_{1} / \mathrm{VC}(\%)$ & $69.2(9.8)$ & $59.2 \quad(10.2)$ & $44.4(9.3)^{\star \star}$ & $30.6(5.9)^{\star}$ \\
\hline
\end{tabular}

$\mathrm{FEV}_{1}=$ forced expiratory volume in one second $\mathrm{FVC}=$ forced vital capacity; $\mathrm{VC}=$ relaxed vital capacity; $\mathrm{FEV}_{1} /(\mathrm{F}) \mathrm{VC} \%=\mathrm{FEV}_{1} /(\mathrm{F}) \mathrm{VC}$ ratio expressed as a percentage.

Data are means (SD).

${ }^{\star} \mathrm{p}<0.05 ;{ }^{\star \star} \mathrm{p}<0.01 ;{ }^{\star \star \star} \mathrm{p}<0.001$ compared with the adjacent less severe category of $\mathrm{FEV}_{1}$ impairment (one way ANOVA with post-hoc comparison).

$t \dagger p<0.01$ severe versus no impairment; $+\dagger \dagger p<0.001$ severe versus no impairment.
Details of age, sex, smoking history, use of inhaled steroids, and co-morbidity are shown in table 1 . The group was predominantly male (58\%), $49 \%$ were ex-smokers and $45.5 \%$ were current smokers, and $48 \%$ were receiving long term inhaled steroid therapy.

Co-morbid conditions were present in 44 patients and included hypertension $(\mathrm{n}=24)$, ischaemic heart disease $(\mathrm{n}=19)$, atrial fibrillation $(n=4)$, diabetes mellitus $(n=7)$, cerebrovascular disease $(n=5)$, and peripheral vascular disease $(n=4)$. Fifteen patients had more than one co-morbid condition (most commonly hypertension with ischaemic heart disease).

\section{LUNG FUNCTION TESTS}

Pre-bronchodilator spirometry

One hundred and eight patients completed pre-bronchodilator spirometric tests. The patients were stratified according to the degree of impairment of the $\mathrm{FEV}_{1}$ expressed as a percentage of the value predicted for age, sex, and height and classified as normal $(\geqslant 80 \%)$, mildly (60-79\%), moderately $(40-59 \%)$ or severely impaired $(<40 \%)$ as recommended in the national guidelines. ${ }^{3}$

Thirty two patients $(30 \%)$ had a normal $\mathrm{FEV}_{1}, 19$ (18\%) had mild impairment, 36 (33\%) moderate impairment, and 21 (19\%) severe impairment of $\mathrm{FEV}_{1}$. There was no difference in age between the four groups (table 1) and the ratio of men to women was similar in all groups except those with severe impairment of $\mathrm{FEV}_{1}$ where men predominated ( $\mathrm{p}=$ 0.0035). Median consumption of cigarettes measured in pack years was not significantly different between the four groups but there were more ex-smokers among those with severe impairment of $\mathrm{FEV}_{1}(\mathrm{p}=0.02)$ and a larger proportion $(81 \%)$ of patients with severe impairment of $\mathrm{FEV}_{1}$ were receiving long term inhaled steroids $(\mathrm{p}<0.0005)$.

Table 2 shows the mean values for $\mathrm{FEV}_{1}$, FVC, and relaxed VC for each of the four groups. The $\mathrm{FEV}_{1}$ showed the expected differences between the groups classified by the BTS criteria but both relaxed and forced vital capacity were preserved within the normal range in patients with mild and moderate disease. However, the mean value for $(F) V C$ (percentage predicted) for these patients was at the lower end of the normal range and significantly lower than for patients without 


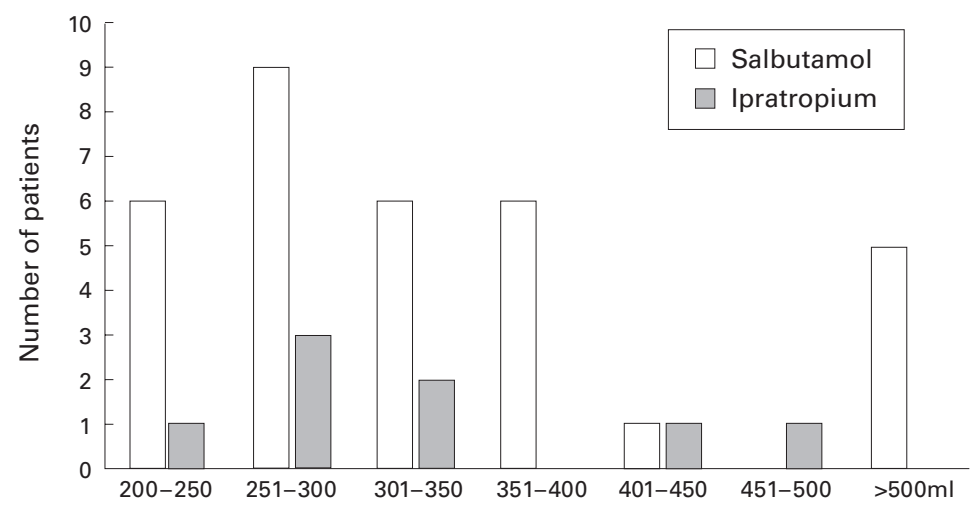

Figure 1 Number of patients with significant reversibility ( $\geqslant 200 \mathrm{ml}$ and $\geqslant 15 \%$ over the baseline value) of FEV $V_{1}$ categorised by the size of the response. Results are given for subjects who responded to salbutamol or ipratropium bromide alone (four subjects responded to both bronchodilators).

impairment of $\mathrm{FEV}_{1}$ (difference of the means for FVC and VC between patients with mild and no impairment of $\mathrm{FEV}_{1} 15.4$ percentage points (95\% CI 7.5 to $23.3, \mathrm{p}=0.0001)$ and 14.9 percentage points ( $95 \%$ CI 6.7 to 23.0 , p $=0.0003)$; difference of the means for FVC and VC between patients with moderate and no impairment of $\mathrm{FEV}_{1} 21.1$ percentage points $(95 \%$ CI 14.1 to $28.1, \mathrm{p}<0.0001)$ and 17.1 percentage points (95\% CI 9.7 to 24.6 , $\mathrm{p}<0.0001)$ ). Patients with severe disease had average values for FVC and VC below the normal range (difference in the means for FVC and VC 41.5 percentage points (95\% CI 33.2 to $49.7, \mathrm{p}<0.0001)$ and 37.3 percentage points (95\% CI 29.2 to $45.4, \mathrm{p}<0.0001)$ compared with patients with a normal $\mathrm{FEV}_{1}$ ).

Impairment of the $\mathrm{FEV}_{1} / \mathrm{FVC}$ or $\mathrm{FEV}_{1} / \mathrm{VC}$ ratios worsened with the severity of disease (table 2). In the group of 32 patients without impaired $\mathrm{FEV}_{1} 13$ had an abnormal $\mathrm{FEV}_{1} / \mathrm{VC}$ ratio $(<70 \%)$ ranging from $46.6 \%$ to $68.8 \%$ but only 11 had an abnormal $\mathrm{FEV}_{1} / \mathrm{FVC}$ ratio.

\section{Post-bronchodilator spirometry}

One hundred and six patients completed spirometric tests after the inhalation of both bronchodilators. For patients with no impairment of $\mathrm{FEV}_{1}$ and an $\mathrm{FEV}_{1} / \mathrm{VC}$ ratio of $\geqslant 70 \%$ the difference between the mean pre- and postbronchodilator value for $\mathrm{FEV}_{1}$ was $181 \mathrm{ml}(95 \%$

Table 3 Static lung volumes and gas diffusion for 107 patients separated by degree of impairment of FEV

\begin{tabular}{|c|c|c|c|c|}
\hline & \multicolumn{4}{|c|}{ Impairment of $F E V_{1}$} \\
\hline & None $(n=31)$ & Mild $(n=19)$ & Moderate $(n=36)$ & Severe $(n=21)$ \\
\hline RV (l) & $2.02(0.44)$ & $2.45(0.65)$ & $3.09(0.69)^{\star \star}$ & $3.73(0.79)^{\star}$ \\
\hline $\mathrm{RV}$ (\% predicted) & $96.0 \quad(17.1)$ & $113.4(26.6)^{\star}$ & $138.3(28.6)^{\star}$ & $155.1(31.5)^{\star}$ \\
\hline TLC (1) & $5.65(1.24)$ & $5.81(1.14)$ & $6.35(1.31)$ & $6.5 \quad(1.28)$ \\
\hline TLC (\% predicted) & $102.3(11.8)$ & 103.1 & 110.6 & $106.4 \quad(12.9)$ \\
\hline RV/TLC (\%) & $36.3(5.9)$ & $42.1(7.3)^{\star}$ & $49.1(7.7)^{\star \star}$ & $57.8(7.7)^{\star \star}$ \\
\hline RV/TLC (\% predicted) & $92.4 \quad(12.6)$ & $107.1(14.6)^{\star}$ & $122.5(18.4)^{\star}$ & $142.3(21.4)^{\star \star}$ \\
\hline TLCO $(\mathrm{mmol} / \mathrm{min} / \mathrm{kPa})$ & $7.66(2.39)$ & $7.6 \quad(2.3)$ & $6.28(2.1)+\dagger$ & 5.5 (1.67) $+\dagger$ \\
\hline TLCO (\% predicted) & 96.9 (23.6) & 94.6 (21.1) & 79.4 (21.5) & $69.3(18.1)+\dagger$ \\
\hline $\mathrm{Kco}(\mathrm{mmol} / \mathrm{min} / \mathrm{kPa} / \mathrm{l})$ & $1.5(0.3)$ & $1.57(0.45)$ & $1.26(0.43) \dagger$ & $1.22(0.38) \dagger$ \\
\hline KCO (\% predicted $)$ & 104.7 (23.9) & $111.3(30.8)$ & $90.5(30.9)$ & $94.1(26.3)$ \\
\hline
\end{tabular}

$\mathrm{RV}=$ residual volume; TLC $=$ total lung capacity; TLCO $=$ carbon monoxide gas transfer factor; $\mathrm{KCO}=$ carbon monoxide gas tranfer coefficient (TLCo divided by effective alveolar volume). All values are means $(\mathrm{SD})$.

${ }^{\star} \mathrm{p}<0.05 ;{ }^{\star \star} \mathrm{p}<0.01 ;{ }^{\star \star \star} \mathrm{p}<0.001$ compared with the adjacent less severe category of $\mathrm{FEV}_{1}$ impairment (one way ANOVA with post-hoc comparison).

$t p<0.05$ severe and moderate versus mild impairment; $t+p<0.01$ severe and moderate versus no impairment; $\dagger+\mathrm{t}<0.001$ severe versus no impairment.
CI 121 to 240, $\mathrm{p}<0.0001$ ); for those with no impairment of $\mathrm{FEV}_{1}$ but an $\mathrm{FEV}_{1} / \mathrm{VC}$ ratio of $<70 \%$ the difference between the means was $317 \mathrm{ml}(95 \%$ CI 125 to $509, \mathrm{p}=0.0001)$; and for those with mild, moderate, and severe disease the differences in the means were $258 \mathrm{ml}$ (95\% CI 203 to $314, \mathrm{p}<0.0001), 352 \mathrm{ml}(95 \%$ CI 286 to $419, \mathrm{p}<0.0001)$, and $250 \mathrm{ml}(95 \% \mathrm{CI}$ 185 to $314, \mathrm{p}<0.0001$ ), respectively.

The difference between the mean pre- and post-bronchodilator VC was $137 \mathrm{ml}(95 \%$ CI 50 to $223, p=0.0007$ ) for patients with no impairment of $\mathrm{FEV}_{1}$ and an $\mathrm{FEV}_{1} / \mathrm{VC}$ ratio of $\geqslant 70 \% ; 242 \mathrm{ml}(95 \%$ CI 71 to $413, \mathrm{p}=0.001)$ for patients with no impairment of $\mathrm{FEV}_{1}$ and an $\mathrm{FEV}_{1} / \mathrm{VC}$ ratio of $<70 \% ; 310 \mathrm{ml}(95 \% \mathrm{CI}$ 213 to $407, \mathrm{p}<0.0001)$ for patients with mild disease; $453 \mathrm{ml}$ (95\% CI 348 to 558, $\mathrm{p}<0.0001)$ for patients with moderate disease, and $505 \mathrm{ml}(95 \%$ CI 365 to $646, \mathrm{p}<0.0001)$ for patients with severe disease.

When disease severity was assessed using the post-bronchodilator $\mathrm{FEV}_{1}$ (\% predicted value), 43 patients $(41 \%)$ were classified as normal whereas 33 patients (31\%) were classified as mildly impaired, $17(16 \%)$ as moderately impaired, and $13(12 \%)$ as severely impaired.

\section{Reversibility}

One hundred and six patients underwent reversibility testing, of whom $19(18 \%)$ had a normal $\mathrm{FEV}_{1}$ ( $\geqslant 80 \%$ predicted) and no evidence of airflow obstruction $\left(\mathrm{FEV}_{1} / \mathrm{VC} \geqslant 70 \%\right)$; $13(12 \%)$ had a normal $\mathrm{FEV}_{1}$ but an impaired $\mathrm{FEV}_{1} / \mathrm{VC}$ ratio of $<70 \% ; 18(17 \%)$ had severe impairment of $\mathrm{FEV}_{1}, 35$ (33\%) had moderate impairment, and $21(20 \%)$ had mild impairment of $\mathrm{FEV}_{1}$. The BTS guidelines define a significant bronchodilator response as an increase in $\mathrm{FEV}_{1}$ of at least $200 \mathrm{ml}$ and $15 \%$ from the baseline value. Such a response to either salbutamol or ipratropium bromide alone was seen in three patients $(23 \%)$ with a normal $\mathrm{FEV}_{1}$ and airflow obstruction, in seven patients (39\%) with mild impairment, in $19(54 \%)$ with moderate impairment, and in eight $(38 \%)$ with severe impairment of $\mathrm{FEV}_{1}$. The absolute bronchodilator response showed a wide range (fig 1) and in 11 patients the $\mathrm{FEV}_{1}$ increased to above $80 \%$ of the predicted value from a median prebronchodilator $\mathrm{FEV}_{1}$ of $72.2 \%$ (IQR $=65.2-$ $76.7)$ to $83.5 \%(\mathrm{IQR}=81.1-86.5)$.

Another parameter used to assess bronchodilator reversibility is the VC, where a significant bronchodilator response is defined as an increase of at least $330 \mathrm{ml} .{ }^{12}$ We found such a response in VC in two patients $(15 \%)$ with a normal $\mathrm{FEV}_{1}$ and $\mathrm{FEV}_{1} / \mathrm{VC}$ ratio of $<70 \%$; in seven patients $(39 \%)$ with mild impairment of $\mathrm{FEV}_{1}$, in $16(46 \%)$ with moderate impairment and in 11 patients $(52 \%)$ with severe impairment of $\mathrm{FEV}_{1}$. Overall, $14(39 \%)$ of the 36 patients with a VC response did not show a significant change in $\mathrm{FEV}_{1}$ to the same bronchodilator.

\section{Static lung volumes}

Static lung volumes and gas diffusion were measured in 107 patients and the results are summarised in table 3. 

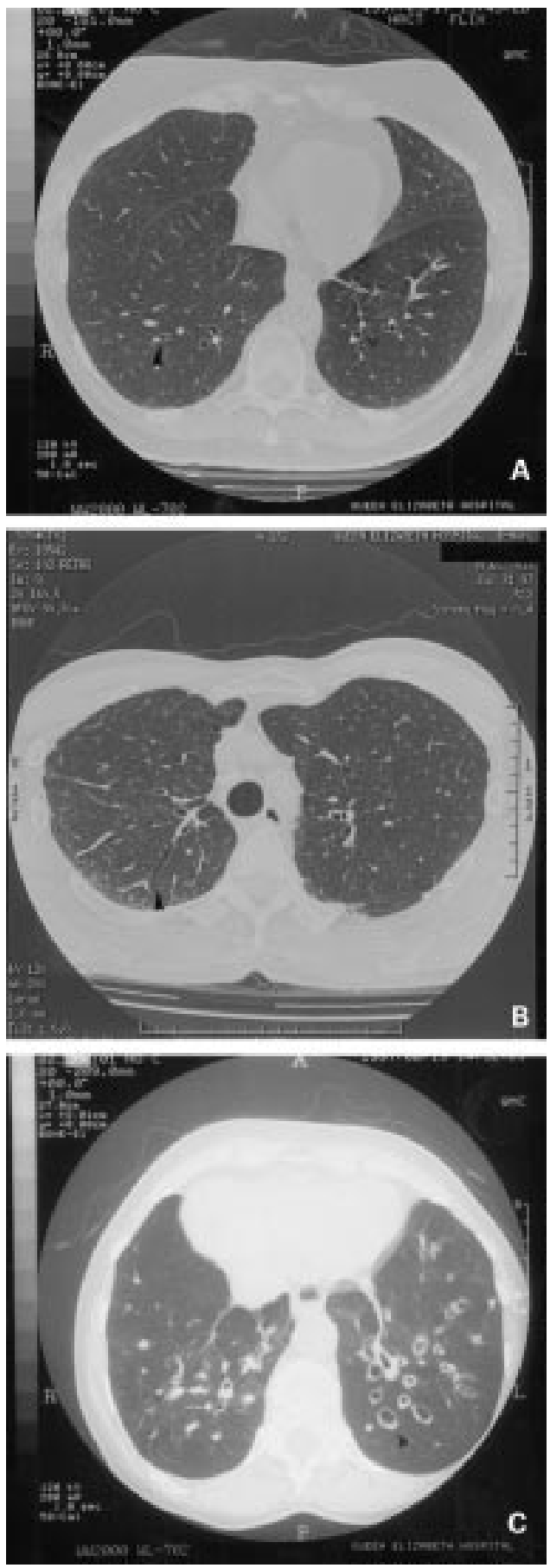

Figure 2 Representative scans of (A) tubular, (B) varicose, and $(C)$ cystic bronchiectasis with the abnormal areas arrowed.

Table 4 HRCT appearances in 108 patients separated by degree of impairment of FEV

\begin{tabular}{|c|c|c|c|c|}
\hline & \multicolumn{4}{|c|}{ Impairment of $F E V_{1}$} \\
\hline & $\begin{array}{l}\text { None } \\
(n=32)\end{array}$ & $\begin{array}{l}\text { Mild } \\
(n=19)\end{array}$ & $\begin{array}{l}\text { Moderate } \\
(n=36)\end{array}$ & $\begin{array}{l}\text { Severe } \\
(n=21)\end{array}$ \\
\hline Normal & 15 & 9 & 10 & 5 \\
\hline \multicolumn{5}{|l|}{ Emphysema } \\
\hline Limited ${ }^{\star}$ & 11 & 7 & 16 & 6 \\
\hline Extensive $^{\star}$ & 1 & 1 & 7 & 5 \\
\hline \multicolumn{5}{|l|}{ Bronchiectasis } \\
\hline Tubular $^{\star}$ & 9 & 4 & 7 & 2 \\
\hline Cystic/varicose & 2 & 0 & 1 & 6 \\
\hline Emphysema and bronchiectasis & 6 & 2 & 5 & 3 \\
\hline
\end{tabular}

^Lung function not available for one patient.
The residual volume was significantly increased, both as an absolute value and when expressed as a percentage of the predicted value, as the severity of $\mathrm{FEV}_{1}$ impairment increased. This was associated with an increase in the RV/TLC ratio indicating increasing air trapping. The carbon monoxide transfer factor (TLCO) was significantly reduced only in the group with severely impaired $\mathrm{FEV}_{1}$ (difference in means $2.16 \mathrm{mmol} / \mathrm{min} / \mathrm{kPa}(95 \%$ CI 0.96 to 3.37, $\mathrm{p}=0.0004$ ) compared with those in whom there was no impairment of the $\mathrm{FEV}_{1}$ ) whereas the transfer coefficient (KCO) was reduced in both those with moderate and severe impairment of $\mathrm{FEV}_{1}$ (difference in the means $0.31 \mathrm{mmol} / \mathrm{min} / \mathrm{kPa} / 1(95 \%$ CI 0.06 to $0.56, \mathrm{p}=0.0073)$ and $0.34 \mathrm{mmol} / \mathrm{min} / \mathrm{kPa} / \mathrm{l}$ $(95 \%$ CI 0.079 to $0.61, \mathrm{p}=0.0061)$, respectively, compared with patients with mildly impaired $\mathrm{FEV}_{1}$ ).

HRCT SCANNING

Normal parenchymal appearances were reported for $39(35 \%)$ scans and $17(15 \%)$ scans had evidence of both emphysema and bronchiectasis.

\section{Emphysema}

Emphysematous change was identified on 56 (51\%) high resolution CT scans which was confined to the upper lobes in $41(73 \%)$. It was extensive, affecting the lower lobes and, in some instances, the middle lobe and lingula in 15 patients $(27 \%)$. Patients with radiological evidence of emphysema had a significantly higher consumption of cigarettes than those without (median pack years 51 (IQR 30-79) and 35 (IQR 17-62), respectively, $\mathrm{p}<0.05$ ).

\section{Bronchiectasis}

Bronchiectasis was noted on 32 (29\%) high resolution CT scans and typical examples are shown in fig 2 . Among the patients with bronchiectasis the disease was cystic in five patients $(15.5 \%)$, varicose in four $(12.5 \%)$, and tubular in 23 patients $(72 \%)$. Twenty six of these 32 patients had a history of smoking but all the lifelong non-smokers $(n=6)$ had bronchiectasis which was tubular in five (table 4).

\section{Pulmonary nodules}

Unsuspected pulmonary nodules were seen on nine $(8 \%)$ scans. A biopsy sample was taken from one and was found to be a resectable adenocarcinoma, and one patient was diagnosed with mediastinal small cell lung cancer six months after the initial scan although the nodule remained unchanged. Five of the patients have had repeat scans which have shown no change over 6-18 months; in one patient the nodule was no longer visible on the repeat scan and the remaining patient declined a further scan.

RELATIONSHIP BETWEEN LUNG FUNCTION AND HRCT SCANNING

Both lung function tests and CT scans were normal in only 10 patients $(9 \%)$. The proportion of patients with a normal scan was similar in the groups of patients categorised by 
Table 5 Lung function for patients with radiological evidence of emphysema or bronchiectasis

\begin{tabular}{|c|c|c|c|c|}
\hline & \multicolumn{2}{|l|}{ Emphysema } & \multicolumn{2}{|l|}{ Bronchiectasis } \\
\hline & Limited $(n=40)$ & Extensive $(n=14)$ & Tubular $(n=22)$ & Varicose/cystic $(n=9)$ \\
\hline $\mathrm{FEV}_{1}$ & $58.6(47.2-80.5)$ & $44.1(31.2-52.9)^{\star \star}$ & $68.7(48.8-94.6)$ & 35.9 (24.4-64.3)\# \\
\hline $\mathrm{VC}$ & $100.0(87.3-114.2)$ & $96.7(77.7-118.1)$ & $111.1(88.5-122.6)$ & $73.6(59.1-108.3) \#$ \\
\hline RV/TLC & $111.5(97.8-133.8)$ & $125.5(104.8-141.3)$ & $108.0(92.0-128.0)$ & $133.0(96.5-139.0)$ \\
\hline TLC & $110.5(100.0-121.8)$ & $118.5(103.3-122.3)$ & $108.0(101.0-120.0)$ & $105.0(96.0-106.5)$ \\
\hline TLCO & $80.0(69.5-88.5)$ & $52.0(43.8-61.3)^{\star \star \star}$ & $78.5(60.5-108.0)$ & $82.0(66.5-102.0)$ \\
\hline Kсo & $90.0(79.3-100.0)$ & $56.0(50.8-63.5)^{\star \star \star}$ & $88.5(62.8-119.8)$ & $107.0(85.5-128.5)$ \\
\hline
\end{tabular}

$\mathrm{FEV}_{1}=$ forced expiratory volume in one second $\mathrm{VC}=$ vital capacity $; \mathrm{RV}=$ residual volume; $\mathrm{TLC}=$ total lung capacity; TLCO = carbon monoxide gas transfer factor; $\mathrm{KCO}=$ carbon monoxide gas tranfer coefficient (TLCo divided by effective alveolar volume). Data are percentage of the predicted value and are given as median with the interquartile range in parentheses. ${ }^{\star \star} \mathrm{p}<0.005,{ }^{\star \star \star} \mathrm{p}<0.001$ limited versus extensive emphysema (Mann Whitney U test).

$\# \mathrm{p}<0.05$ varicose/cystic versus tubular bronchiectasis.

degree of $\mathrm{FEV}_{1}$ impairment . Similarly the proportion of patients with emphysema or bronchiectasis did not differ significantly between the four groups.

Patients with extensive emphysema had more severe impairment in both $\mathrm{FEV}_{1}$ and gas transfer than patients with limited emphysema (table 5). Patients with varicose or cystic bronchiectasis were also found to have severe impairment of $\mathrm{FEV}_{1}$ and this was greater than in patients with tubular disease (table 5).

\section{SPUTUM COLOUR IN THE STABLE STATE AND BRONCHIECTASIS}

Ninety one patients $(83 \%)$ provided a spontaneously expectorated sputum sample. Of the remaining 19 patients who were unable to expectorate sputum on the day of the assessment, six had radiological evidence of tubular and one had evidence of varicose bronchiectasis. Sputum colour for the patients with and without radiological evidence of bronchiectasis is shown in fig 3. The patients with bronchiectasis had a higher sputum number in the stable clinical state than the non-bronchiectatic group $(p=0.0006)$ although the range was wide (median number for bronchiectasis 3 (IQR 2-4) compared with 2 (IQR 2-3) for those without bronchiectasis). Mucopurulent sputum, assigned the number 5, occurred significantly more frequently in the patients with cystic and varicose bronchiectasis than in the patients with tubular bronchiectasis $(\mathrm{p}=$ 0.0011 , Fisher's exact test). Indeed, when these patients were excluded, the distribution of spu-

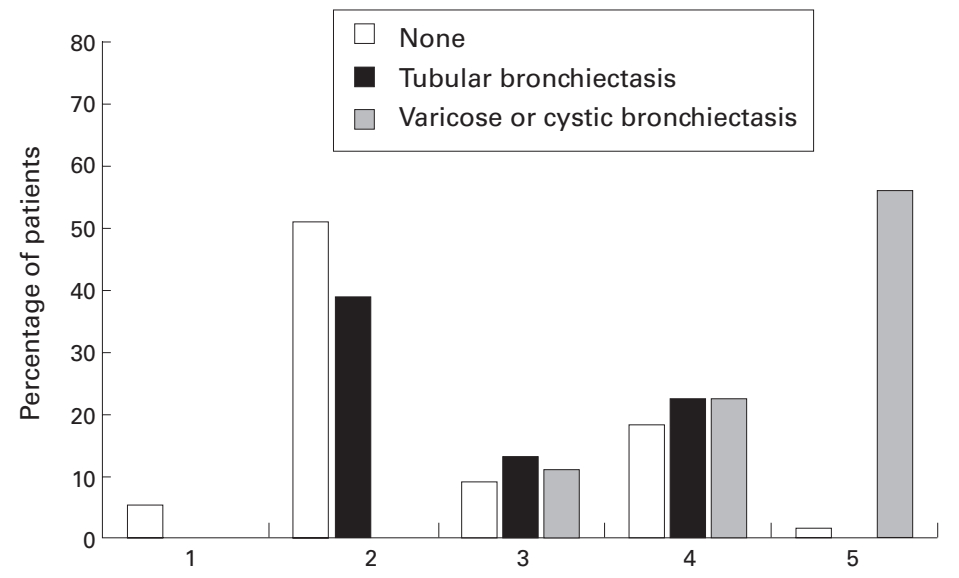

Figure 3 Number of patients with sputum colour in each of the number categories. The patients are divided into those with no bronchiectasis, those with tubular bronchiectasis, and those with varicose or cystic bronchiectasis. tum colour was similar for patients with or without tubular bronchiectasis (fig 3).

\section{Discussion}

This paper describes the physiological and radiological features of patients in primary care who were diagnosed as having COPD by their general practitioner. Formal lung function testing indicated that the $\mathrm{FEV}_{1}$ was in the normal range in $30 \%$ of the patients, suggesting that COPD is overdiagnosed in primary care if the BTS criteria for the diagnosis are applied, since these are based on the degree of impairment of $\mathrm{FEV}_{1}$ alone. However, among the patients with a normal $\mathrm{FEV}_{1}, 41 \%$ had evidence of airflow obstruction with an $\mathrm{FEV}_{1} / \mathrm{VC}$ ratio of $<70 \%$ which indicates that airflow obstruction was present in many of the patients with an $\mathrm{FEV}_{1}$ in the "normal" range and demonstrates the value of measuring the vital capacity when assessing patients with COPD. In the remaining patients in whom the $\mathrm{FEV}_{1}$ was reduced a range of impairment was found with $18 \%$ having mild, $33 \%$ moderate, and $19 \%$ severe impairment.

The national guidelines suggest that patients with mild disease are pre-symptomatic within the community. ${ }^{3}$ It would be predicted therefore that the patients studied here who presented to their general practitioner with an acute exacerbation of COPD would have moderate or severe disease. However, since $48 \%$ of the study patients had mild or no impairment of the $\mathrm{FEV}_{1}$, it appears that these patients require the use of health care resources more often than expected.

Our study may have overestimated the proportion of patients with mild and moderate disease in the community since we did not include patients who were thought to require treatment with oral corticosteroids or hospital admission. Two studies from Europe support the supposition that such patients may have had more severe disease. In a retrospective analysis of pre-discharge spirometric tests in 112 patients admitted to hospital with an infective exacerbation of COPD, $73 \%$ had an $\mathrm{FEV}_{1}$ of less than $50 \%$ of the predicted value. ${ }^{16}$ In addition, a recent study from Spain found that general practitioners prescribed oral corticosteroids in $43 \%$ of exacerbations in patients with predominantly moderate and severe COPD. ${ }^{17}$ However, there is no similar published information on the proportion of patients with acute exacerbations treated with 
oral corticosteroids in primary care in the UK. Overall, the proportion of patients with mild disease presenting to their general practitioner with an exacerbation is probably smaller than we have found. Nevertheless, the results described here still indicate that such patients do present themselves to the health care sector and clearly this would be an important group to identify and in whom to instigate preventative measures such as smoking cessation.

The determination of bronchodilator reversibility is important to establish the best achievable value for the $\mathrm{FEV}_{1}$, to direct treatment, and to identify patients with a large increase who are predominantly asthmatic. In addition, the post-bronchodilator $\mathrm{FEV}_{1}$ has been shown to relate more closely to survival than the prebronchodilator value. ${ }^{18}{ }^{19}$ In our study group $72 \%$ of patients had a post-bronchodilator $\mathrm{FEV}_{1}$ of $>60 \%$ of the predicted value, which implies a relatively good prognosis in the majority. However, most of our patients were elderly and survival has been shown to be worse in patients over the age of $65 .{ }^{19}$

In guidelines on the management of COPD various criteria are proposed to define a significant bronchodilator response and there is no agreement on the degree of response that indicates an underlying diagnosis of asthma. ${ }^{347}$ The summary of the national guidelines, which was sent to general practitioners, suggests that a substantial increase in the $\mathrm{FEV}_{1}$ of $>500 \mathrm{ml}$ may indicate an underlying diagnosis of asthma. Only five patients studied here showed such a response, suggesting that few asthmatics are mistakenly diagnosed as having COPD. However, this low incidence of asthmatic response could reflect the development of fixed airflow obstruction in previous asthmatic subjects with time, as most of the patients were elderly.

There is a consensus that patients with COPD can have a limited degree of bronchodilator reversibility and this was confirmed in the current study. A significant increase in the $\mathrm{FEV}_{1}(>200 \mathrm{ml}$ ) was found in just under half of the patients which is higher than the $36 \%$ reported previously by Nisar et al. ${ }^{20}$

The patients in our study with reversibility had a range of $\mathrm{FEV}_{1}$ responses to bronchodilators and more improved following a $\beta_{2}$ agonist than with an anticholinergic agent, which is generally regarded as the bronchodilator of choice in COPD. The latter finding is probably explained by the sequence in which we administered the bronchodilators and it is likely that a higher proportion of patients would have shown a response to the anticholinergic agent if it had been administered alone. Nevertheless, our findings suggest that $\beta_{2}$ agonists have a useful role in the treatment of airflow limitation in COPD.

Two recent studies have shown that bronchodilators reduce pulmonary hyperinflation even in the absence of a significant change in $\mathrm{FEV}_{1}$, and that measurements of reduced pulmonary hyperinflation are better predictors of therapeutic benefit. ${ }^{21} 22$ The value of assessing changes in parameters which indirectly measure reduced air trapping is shown by the fact that, in our study, $39 \%$ of the patients in whom the VC had increased significantly in response to bronchodilators did not have a significant increase in the $\mathrm{FEV}_{1}$.

An important finding of our study was the high prevalence of radiological bronchiectasis among patients diagnosed with COPD. CT scanning with a high resolution algorithm is now the investigation of choice to confirm a diagnosis of bronchiectasis ${ }^{13}$ and, using generally accepted criteria, ${ }^{13}{ }^{14}$ we found that almost one third of the patients had bronchiectasis. It is likely that bronchiectasis is generally underdiagnosed, particularly in smokers where cough and sputum production are assumed to be due to cigarette smoke and COPD. ${ }^{23}$ In secondary care Currie et al found an incidence of bronchiectasis of $70 \%$ by bronchography and Smith et al reported an incidence of $68 \%$ by HRCT scanning. ${ }^{24}{ }^{25}$ However, both of these studies were based on patients referred for investigation of cough and sputum production and most were non-smokers, which may explain the high incidence.

In our study most of the patients with bronchiectasis were smokers and were clinically indistinguishable from the group as a whole. Smith et $a l^{25}$ suggested that production of purulent sputum in the stable clinical state was highly suggestive of bronchiectasis. Our study supports this observation in cystic and varicose bronchiectasis which was a feature of most patients $(83 \%)$ with sputum production classified as colour number 5 . However, patients with tubular bronchiectasis could not be differentiated on clinical grounds or by sputum characteristics and thus may represent a different aetiological and clinical type of bronchiectasis from that recognised by traditional methods. Clearly, further studies are required to determine morbidity and prognosis in this radiological subgroup.

HRCT scanning is also sensitive and accurate in the diagnosis of emphysema ${ }^{26}$ and we found that half of the patients had radiological evidence of emphysema which was related to heavier cigarette smoking, as has been reported by others. ${ }^{27}{ }^{28}$ In the present study we made no attempt to quantify the degree of emphysema but, when present, it was usually confined to the upper lobes. In this group there was no relationship with the degree of $\mathrm{FEV}_{1}$ impairment and $75 \%$ had a TLCO in the normal range. In contrast, the 15 patients with emphysema involving the lower lobes showed more severe impairment of $\mathrm{FEV}_{1}$ and TLCO which is consistent with the study by Gurney et $a l^{27}$ who suggested that extensive emphysematous destruction of the upper lobe could occur before lung function was impaired.

Nine percent of our scans showed the presence of an unexpected pulmonary nodule. So far (two years later) only two patients have had a firm diagnosis of carcinoma made and one has proved resectable. The remaining nodules remain unchanged which suggests they are benign; however, this view has been challenged ${ }^{29}$ and the patients continue to be under review as they remain at increased risk from malignancy due to smoking. The 
relatively high rate of detection of nodules has implications for both the patients and health care providers and further studies are indicated to determine the cost effectiveness of HRCT scanning in screening and management of patients with COPD.

In conclusion, our study confirms that COPD in primary care is a heterogeneous disease. One third of patients with this diagnosis do not fulfil the proposed criteria $^{3}$ (which emphasises the need for spirometric measurements of a high standard) and the remainder have a wide range of lung function impairment. Bronchiectasis is present in a significant proportion of patients although the implications of this finding remain unknown. However, the results of our study suggest that more careful characterisation of COPD patients in primary care is required to determine the applicability of current therapeutic guidelines and when drawing conclusions from clinical trials conducted in this population.

We thank all general practitioners for referring their patients for participation in this study. We also thank Mrs B Leung, Mrs K Verbeet and Mrs M Henson for their involvement in the recruitment and care of the patients.

Funding: This study was funded by an unrestricted educational grant from GlaxoWellcome.

1 Murray CJL, Lopez AD. Evidence-based health policy: lessons from the global burden of disease study. Science 1996;274:740-3.

2 Office of Population Censuses and Surveys. Morbidity statistics from general practice. Fourth national study 1991-1992. London: HMSO, 1995.

3 COPD Guidelines Group of the Standards of Care Committee of the British Thoracic Society. BTS guidelines for the management of chronic obstructive pulmonary disease. Thorax 1997;52(Suppl 5):S1-28.

4 American Thoracic Society. Standards for the diagnosis and care of patients with chronic obstructive pulmonary care of patients with chronic obstructive pulmonary
disease. Am ₹ Respir Crit Care Med 1995;152:S77-120.

5 Snider G. Defining chronic obstructive pulmonary disease. In: Calverley PMA, Pride NB, eds. Chronic obstructive In: Calverley PMA, Pride NB, eds. Chronic obstructive

pulmonary disease. London: Chapman \& Hall, 1995: 1-8. Snider GL. 1. Changes in COPD occurrence. Chronic obstructive pulmonary disease: A definition and implica-
tions of structural determinants of airflow obstruction for tions of structural determinants of airflow obstruction for epidemiology. Am Rev Respir Dis 1989;140:S3-8.

7 Siafakas NM, Vermeire P, Pride NB, et al. Optimal assessment and management of chronic obstructive pulmonary disease (COPD). Eur Respir F 1995;8:1398420
8 Badgett RG, Tanaka DJ, Hunt DK, et al. Can moderate chronic obstructive pulmonary disease be diagnosed by 188-96.

9 Kesten S, Chapman KR. Physician perceptions and management of COPD. Chest 1993;104:254-8.

10 Wolkove N, Dajczman E, Colacone A, et al. The relationship between pulmonary function and dyspnea in obstructive lung disease. Chest 1989;96:1247-51.

11 Stockley RA, Hill SL, Burnett D. Proteinases in chronic lung infection. Ann NY Acad Sci 1991;624:257-66.

12 British Thoracic Society, Association of Respiratory Technicians and Physiologists. Guidelines for the measurement of respiratory function. Respir Med 1994;88:165-94.

13 Hansell DM. Bronchiectasis. In: Webb WR, ed. Imaging in obstructive pulmonary disease. Philadelphia: WB Saunders, 1998: 107-28.

14 Naidich DP, McCauley DI, Khouri NF, et al. Computed tomography of bronchiectasis. F Computer Assist Tomogr 982;6:437-44.

15 Bergin CJ, Muller NL, Miller RR. CT in the qualitative assessment of emphysema. 7 Thorac Imaging 1986;1:94103.

16 Eller J, Ede A, Schaberg T, et al. Infective exacerbations of chronic bronchitis: relation between bacteriologic etiology and lung function. Chest 1998;113:1542-8.

17 Miravittles M, Mayordomo C, Artes M, et al. Treatment of chronic obstructive pulmonary disease and its exacerbations in general practice. Respir Med 1999;93:173-9.

18 Anthonisen NR, Wright EC, Hodgkin JE. Prognosis in chronic obstructive pulmonary disease. Am Rev Respir Dis 1986;133:14-20.

19 Traver GA, Cline MG, Burrows B. Predictors of mortality in chronic obstructive pulmonary disease. Am Rev Respir Dis 1979;119:895-902

20 Nisar M, Walshaw M, Earis JE, et al. Assessment of reversibility of airway obstruction in patients with chronic obstructive airways disease. Thorax 1990;45:190-4.

21 Tantucci C, Duguet A, Similowski T, et al. Effect of salbutamol on dynamic hyperinflation in chronic obstructive pulmol on dynamic hyperinflation in chronic obstructive pu-

22 O'Donnell DE, Lain M, Webb KA. Spirometric correlates of improvement in exercise performance after anticholinergic therapy in chronic obstructive pulmonary disease. Am $\mathcal{F}$ Respir Crit Care Med 1999;160:542-9.

23 Cole PJ. Bronchiectasis. In: Brewis RAL, Corrin B, Geddes DM, Gibson GJ, eds. Respiratory medicine. London: WB Saunders, 1995: 1286

24 Currie DC, Cooke JC, Morgan AD, et al. Interpretation of bronchograms and chest radiographs in patients with chronic sputum production. Thorax 1987;42:278-84

25 Smith IE, Jurriaans E, Diederich S, et al. Chronic sputum production: correlations between clinical features and findings on high resolution computed tomographic scanning of the chest. Thorax 1996;51:914-8.

26 Stern EJ, Frank MS. CT of the lung in patients with pulmonary emphysema: diagnosis, quantification, and correlation nary emphysema: diagnosis, quantification, and correlation with path.

27 Gurney JW, Jones KK, Robbins RA, et al. Regional distribution of emphysema: correlation of high-resolution CT with pulmonary function tests in unselected smokers. Radiology 1992;183:457-63.

28 Kubo K, Eda S, Yamamoto H, et al. Expiratory and inspiratory chest computed tomography and pulmonary function tests in cigarette smokers. Eur Respir f 1999;13:252-6.

29 Yankelevitz DF, Henschke CI. Does 2-year stability imply 